\title{
Estimating ecotoxicological effects of chemicals on tropical reef-building corals; a systematic review protocol
}

\author{
Dakis-Yaoba Ouédraogo ${ }^{1 *}$ (D), Olivier Perceval ${ }^{2}$, Christine Ferrier-Pagès ${ }^{3}$, Isabelle Domart-Coulon ${ }^{4}$, \\ Laetitia Hédouin ${ }^{5,6}$, Karen Burga ${ }^{7}$, Mireille M. M. Guillaume ${ }^{8,5}$, Christophe Calvayrac ${ }^{9,10}$, Magalie Castelin ${ }^{11}$, \\ Yorick Reyjol $^{12}$ and Romain Sordello ${ }^{12}$
}

\begin{abstract}
Background: Tropical coral reefs cover only ca. $0.1 \%$ of the Earth's surface but host an outstanding biodiversity and provide important ecosystem services to millions of people living nearby. They are currently threatened by global (e.g., climate change) and local (e.g., chemical pollution) stressors that interact in different ways. While global stressors cannot be mitigated by local actions alone, local stressors can be reduced through ecosystem management. A systematic map on the impacts of chemicals arising from anthropogenic activities on tropical reef-building corals, which are the main engineer species of reef ecosystems, was published in 2021. This systematic map gathered an abundant literature (908 articles corresponding to 7937 studies), and identified four well-represented subtopics, amenable to relevant full syntheses. Here, we focused on one of the four subtopics: we aimed to systematically review the evidence on the ecotoxicological effects of chemicals on tropical reef-building corals.

Methods: The evidence will be identified from the recent systematic map on the impacts of chemicals arising from anthropogenic activities on tropical reef-building corals. Especially, all studies in the map database corresponding to the knowledge cluster "evidence on the ecotoxicological effects of chemicals on corals" will be selected. To identify the evidence produced since then, a search update will be performed using a subset of the search string used for the systematic map, and titles, abstracts and full-texts will be screened according to the criteria defining the selected cluster of the map. In addition, as the eligibility criteria for the systematic review are narrower than those used to define the cluster in the systematic map, additional screening will be carried out. The included studies will then be critically appraised and a low, medium, or high risk of bias will be assigned to each study. Data will be extracted from studies and synthesised according to a strategy depending on the type of exposure and outcome. Synthesis will be mainly quantitative but also narrative, aiming to identify toxicity thresholds of chemicals for corals.
\end{abstract}

Keywords: Contamination, Hazard assessment, Hermatypic, Pollution, Scleractinian, Toxicity endpoints

\footnotetext{
*Correspondence: dakis.ouedraogo@gmail.com; dakis-yaoba.ouedraogo@mnhn.fr

1 Direction de l'Expertise, Muséum National d'Histoire Naturelle (MNHN),

75005 Paris, France

Full list of author information is available at the end of the article
}

\section{Background}

Tropical coral reefs cover only ca. $0.1 \%$ of the Earth's surface but they host an outstanding biodiversity [1], with an estimated $32 \%$ of all named marine species found in coral reefs [2]. They also provide important ecosystem services to millions of people living nearby [3, 4], estimated at nearly US\$ 30 billion in net benefits in goods and services to world economies each year [5]. Despite their biological original author(s) and the source, provide a link to the Creative Commons licence, and indicate if changes were made. The images or other third party material in this article are included in the article's Creative Commons licence, unless indicated otherwise in a credit line to the material. If material is not included in the article's Creative Commons licence and your intended use is not permitted by statutory regulation or exceeds the permitted use, you will need to obtain permission directly from the copyright holder. To view a copy of this licence, visit http://creativecommons.org/licenses/by/4.0/. The Creative Commons Public Domain Dedication waiver (http://creativeco mmons.org/publicdomain/zero/1.0/) applies to the data made available in this article, unless otherwise stated in a credit line to the data. 
and economical importance, $75 \%$ of the world's tropical coral reefs are currently threatened by global and local stressors [3, 6, 7]. Between 2009 and 2018, global average hard coral cover declined from 33.3 to $28.8 \%$, which is approximately the equivalent of losing all hard corals currently living on Australia's coral reefs [8]. While the most prominent global threats are represented by seawater warming and acidification [9], local threats are mainly represented by unsustainable or destructive development of coastal areas, excess sedimentation, overfishing, as well as nutrient and chemical pollution resulting from poor land management, urbanisation, agriculture and industry $[10,11]$.

The health of reef ecosystems is largely based on the health of their main engineer species, the reef-building corals, which are key organisms responsible for reef accretion but also form the three-dimensional structures serving as habitat, food, and nursery for thousands of other reef organisms [12]. The vast majority of such corals (Hermatypic corals, sensu [13]) are colonial scleractinian corals (Cnidaria Hexacorallia) living in association with endosymbiotic dinoflagellate algae belonging to the Symbiodiniaceae family [14]. Symbionts are the main nutritional source for corals, and the breakdown of the coral-algal symbiosis, also called coral bleaching may ultimately lead to coral death if prolonged, and affect the overall functioning of coral reef ecosystems [12]. The main factor responsible for coral bleaching is seawater warming [15], but coral symbiosis is also largely impacted in coastal reefs by water pollution, which is a major threat per se [16], exerting direct and indirect toxic effects on coral organisms and algae. Depending on the type of pollution, the host, symbionts or both partners are impacted, through reduced calcification, photosynthesis or fecundity, and enhanced bleaching and oxidative stress, among other damages [17-19]. Water pollution also reduces coral resistance and resilience to thermal stress and acidification [20-22], increases coral disease and pathogen occurrence [23], thereby leading to a sharp decline in coral cover and reef functions ([23], Fig. 1). While global stressors cannot be halted by local actions, local stressors can be reduced through ecosystem management, therefore avoiding the exacerbation of climate change effects by the interaction of multiple stressors [24].

One way for decision-makers to take action for coral reef protection from chemicals is to assess risk, a procedure in which exposure assessment is combined with a quantitative or a qualitative hazard assessment, i.e., the intrinsic properties of a contaminant which make

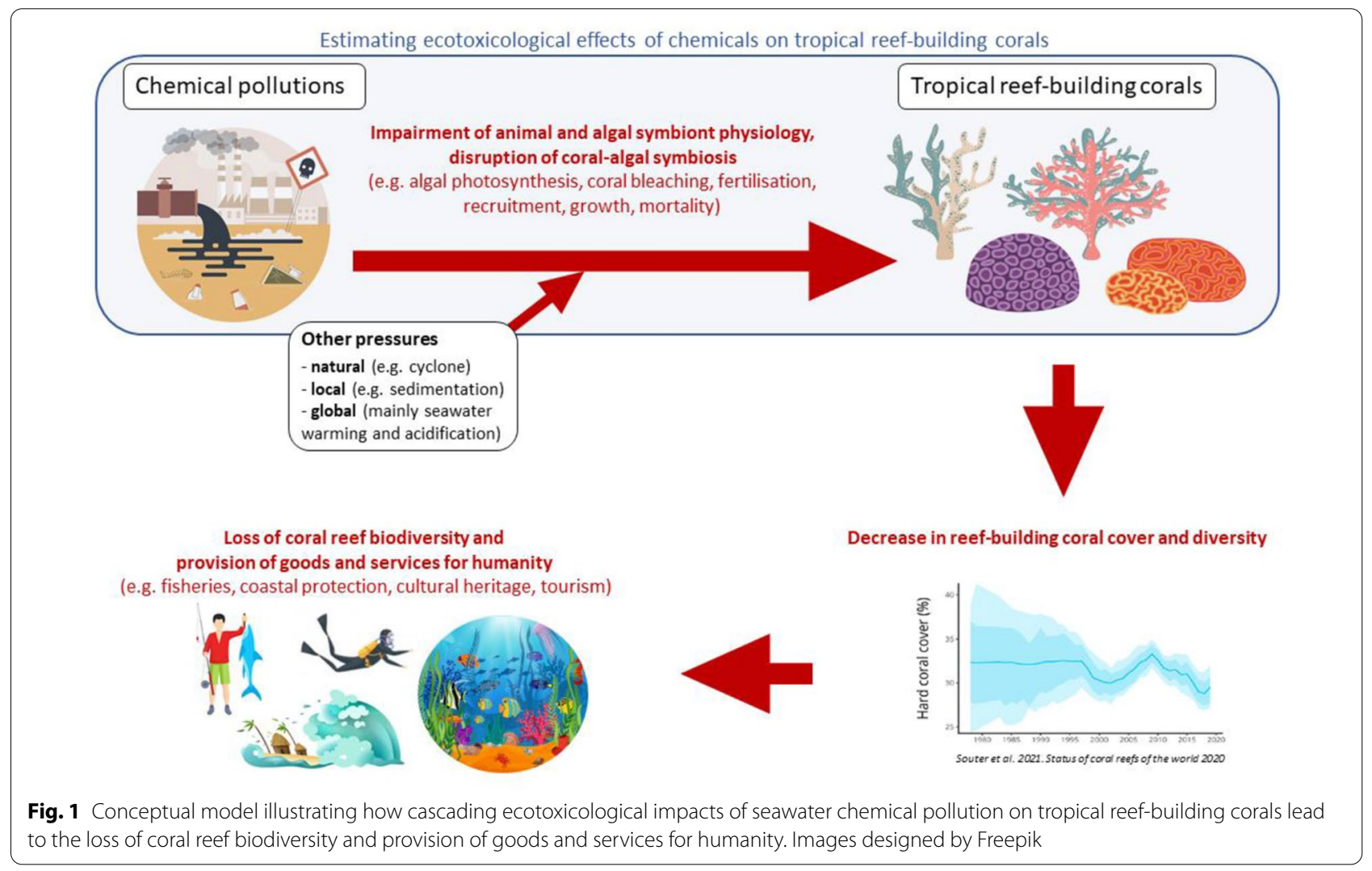


it capable of causing harm to the environment. Principal inputs to hazard/effect assessment are the results of toxicity tests, expressed as measurement endpoints or criteria for effects, such as the No Observed Effect Concentration (NOEC) or the Lowest Observed Effect Concentration (LOEC) for chronic exposure tests, or the median lethal or median effective concentrations (LC50 or EC50, respectively) for short-term exposure tests [25]. In ecological risk assessment, assessment factors (also termed uncertainty or security factors) are generally applied to these measurement endpoints to take into account the uncertainties resulting from the differences in sensitivity between species to contaminant exposure, short-term to long-term toxicity extrapolation, and laboratory data to field impact extrapolation.

In this paper, we aim to systematically review the experimental studies assessing the toxicity of chemicals to tropical reef-building corals to generate accessible and usable knowledge and data that can serve for the calculation of measurement endpoints in ecological risk assessment. To our knowledge, no such review exists yet. However, there are already reviews focusing on the toxicity of one or more categories of chemical to corals, for instance on pesticides, industrial pollutants, hydrocarbons and metals [26], photosystem II herbicides [27], petroleum hydrocarbons [28], or organic ultraviolet filters [29]. With the exception of the review by Mitchelmore et al. published in 2021 [29], none of these reviews mention the method used to collect the studies, so they are not reproducible and the risk of bias due to the selection of particular studies cannot be assessed.

\section{Topic identification and stakeholder input}

Coral reefs of the French Overseas Territories cover $14,280 \mathrm{~km}^{2}$ corresponding to $5 \%$ of the world's total coral reef area [30, 31]. France is the country with the 4th largest coral reef area in the world, after Indonesia (18\% of world total area), Australia (17\%) and the Philippines (9\%) [31], and therefore has substantial responsibility towards coral reef protection. In territories that are subject to strong demographic pressure and increasing anthropisation, the majority of coral reefs are degraded [32]. The French Ministry of Ecology has launched an assignment to assess the impacts of chemicals and nutrients on coral reefs and improve coral reef protection and management at the national scale. The project includes a systematic review to gather and analyse the existing knowledge on the impacts of chemicals on corals. As a first step, in order to know the state of the available literature on the subject, a systematic map on the impacts of chemicals stemming from human activity on tropical reef-building corals was produced and published in the Environmental Evidence Journal in 2021 [33]. A large body of scientific literature was found (908 articles, 7937 studies) and four relevant knowledge clusters were identified: (1) evidence on bioaccumulation of chemicals by corals (2050 studies); (2) evidence on the effects of nutrient enrichment on corals (2496 studies); (3) evidence on the effects of human activities on corals (1127 studies); and (4) evidence on the ecotoxicological effects of chemicals on corals (except nutrient enrichment, 2007 studies). The steering committee of the project, including the French Ministry of Ecology, decided that a systematic review on the ecotoxicological effects of chemicals on corals, based on the knowledge cluster four of the systematic map, should be carried out in order to produce the necessary input data for another part of the project, namely the ecological risk assessment.

\section{Objective of the review Primary question}

The primary question is: What are the toxicity thresholds of chemicals for tropical reef-building corals?

\section{Components of the primary question}

The above primary question has the following key elements:

Population: All tropical reef-building coral species (hermatypic scleractinian species, Millepora species, Heliopora species and Tubipora species). All developmental stages are considered (mobile planula, fixed polyp), as well as all coral compartments including dinoflagellates symbionts "in hospite" and microbiome.

Exposure: All geogenic (e.g., trace metals) and synthetic chemicals (e.g., diuron) for which the exposure concentration is known. Nutrients (e.g., nitrate) are excluded.

Comparator: Population not exposed to chemicals; Population prior to chemical exposure.

Outcomes: All outcomes related to the health status of tropical reef-building corals, from the molecular (e.g., gene expression, enzyme activities) to the colony (e.g., photosynthesis, bleaching) and the population level (e.g., mortality rate).

Type of study: All experimental studies i.e., for which exposure is controlled by the researchers, in laboratory or in the field.

\section{Methods}

The systematic review will follow the Collaboration for Environmental Evidence Guidelines and Standards for Evidence Synthesis in Environmental Management [34] and this protocol conforms to ROSES reporting standards [35] (see Additional file 1). 


\section{Searching for articles}

The evidence will be extracted from the recently published systematic map on the impact of chemicals originating from human activities on tropical reef-building corals [33]. The map searched for literature in two bibliographic databases (Scopus and Web of Science Core Collection, March 19th 2020), three search engines (CORE, July 7th 2020, Google Scholar and GreenFile, July 8th 2020), two dissertations repositories (September 15th 2020), 11 specialist websites (from April 21st to May 29th 2020) and a call for literature (July 13th 2020). A search update will be carried out to identify subsequent published literature. The search update will follow the same protocol as described in the systematic map protocol [36], except that (1) the searches will be limited to the period from the year 2020 onwards; (2) a subset of the search string will be used; and (3) a call for literature will not be performed (see Additional file 2 for details and comparison between the search strategy used for the systematic map and the search update planned for the systematic review). It is very unlikely that a new call for literature will bring additional articles as the search update will cover only two years and the systematic map showed that only one article was finally added through the call for literature [33]. The search string used for the systematic map, which combines terms describing population and exposure, will be adapted to fit the scope of the systematic review, which is narrower than the map. In concrete terms, among the terms describing exposure, the term "nutrient\$" will be removed, as well as the generic terms "contamin"” and "pollut", and all terms describing pressures (e.g., sewage, runoff; see details in Additional file 2). The search string for updating the search is as follows (Web Of Science format):

$\mathrm{TS}=$ (coral\$ AND (toxicant\$ OR chemical\$ OR biocide\$ OR "industrial product\$" OR "consumer product\$" OR "household product\$" OR "biocidal product\$" OR disinfect* OR oil OR metal\$ OR pesticide\$ OR herbicide\$ OR insecticide\$ OR fungicide\$ OR antifoul" OR anti-foul" OR organochlorine\$ OR "flame retardant\$" OR detergent\$ OR "perfluorinated compound\$" OR pharmaceutical\$ OR "personal care product\$" OR cosmetic\$ OR PAH\$ OR petroleum OR hydrocarbon\$ OR microplastic\$ OR nanoparticle\$ OR nano-particle\$ OR "endocrine disrupt" " OR "organic compound\$” OR dispersant\$ OR metalloid\$ OR solvent\$ OR petrochemical\$ OR additive\$ OR preservative\$ OR plasticizer\$ OR hormone\$ OR "transformation product\$" OR "degradation product\$" OR byproduct $\$$ OR by-product\$ OR sunscreen\$ OR "UV filter\$" OR "ultraviolet filter\$" OR antibiotic\$ OR phthalate\$ OR PCB\$ OR cyanide\$ OR chlordecone OR nickel OR copper OR zinc OR cadmium OR mercury OR iron)).

\section{Article screening and study eligibility criteria}

\section{Screening process}

First, the 2007 studies corresponding to the cluster four "evidence on the ecotoxicological effects of chemicals on corals" identified in the systematic map will be selected and the cluster will be updated by adding studies published since the map was produced. For this, the articles retrieved from the search update will be screened for eligibility in the cluster in two successive stages: first on titles and abstracts, and second on full-texts. Articles with unclear eligibility status during the process of title/ abstract screening will be included for full-text screening. Articles without an abstract and retained based on title screening will directly be screened on their full-text. The screening will be performed by one experienced reviewer who has participated in all stages of screening and metacoding for the systematic map and whose decisions have therefore already been checked for consistency (2148 out of 15,177 titles and abstracts (14.2\%) and 180 out of 2700 full-texts $(6.7 \%)$ were independently screened by four reviewers and all disagreements discussed and solved; and 20 out of 908 articles (2\%) were independently coded by six reviewers and all disagreements discussed and solved; [36]). This screening can thus be considered as a continuation of the screening and metacoding for the systematic map. Nevertheless, all doubtful cases regarding eligibility will be discussed with reviewers who participated in consistency checking. We will ensure that reviewers never had to screen or discuss their own articles. The list of articles from the search update rejected or with unclear eligibility status at full-text screening will be provided with reasons for exclusion or explanation of why they could not be classified.

Second, as the eligibility criteria for the systematic review are narrower than those used to define the cluster in the systematic map (see Sect. "Eligibility criteria"), additional screening will be carried out. It will be shared among several reviewers, and any excluded studies will be double-checked by another reviewer. We will ensure that reviewers never had to screen or check their own articles. The list of studies rejected will be provided with reasons for exclusion.

\section{Eligibility criteria}

The eligibility will be assessed using the criteria detailed in Table 1 . The eligibility criteria for the systematic review that are used in addition to those used to define the cluster in the systematic map are (1) the mention of exposure concentrations, (2) the presence of an unexposed population, and (3) a chemical exposure that can be dissociated from other physical disturbances (e.g., sedimentation/ macroparticles). 
Table 1 Eligibility criteria

Include

Population:

All tropical reef-building coral species (hermatypic scleractinian species, Millepora species, Heliopora species and Tubipora species) living in the shallow and the mesophotic zones. All developmental stages are considered (mobile planula, fixed polyp), as well as all coral compartments including dinoflagellates symbionts "in hospite" and microbiome

Exposure:

All geogenic (e.g., trace metals) and synthetic chemicals (e.g., diuron) for which the exposure concentration is known

Exposure to a chemical alone or in combination with another chemical

\section{Comparator:}

Studies comparing population exposed to chemicals and population unexposed to chemicals

Studies comparing population exposed to chemicals and population prior to exposure to chemicals

For chemicals where a solvent is necessary, exposition to the solvent only could be considered as an unexposed population

Outcome:

All outcomes related to the health status of tropical reef-building corals, from the molecular (e.g., gene expression, enzyme activities) to the colony (e.g., photosynthesis, bleaching) and the population level (e.g., mortality rate)

Studies assessing impacts on coral microbiome/symbionts

\section{Language:}

All articles written in English or French (in case a title or an abstract could not be found in English or French, it was directly screened on full-text)

Type of document:

Journal article, book chapter, report, conference proceeding, PhD or MSc thesis

Type of content:

In-situ or ex-situ experimental studies

\section{Exclude}

Cold-water or deep-water corals Ahermatypic corals

Free-living dinoflagellates (not as symbionts in corals)

Studies conducted in coral reefs but not about corals (e.g., about coral reef fishes)

Studies assessing the impact of nutrients (e.g., nitrate) or eutrophication Studies assessing the impact of human activities (e.g., river discharge, distance to a dump or to an industrial effluent source, tourism) on corals without reference to a chemical

Studies in which exposure to a chemical cannot be dissociated from other physical disturbances (e.g., sedimentation/macroparticles)

Studies comparing population exposed to a range of concentrations/levels of chemicals (absence of an unexposed population in the experiment)

Studies reporting evidence of ingestion, concentration or accumulation/ uptake of chemicals (bioaccumulation)

Presentation, editorial material, letter or news item, conference or meeting abstract, poster

Observational studies (field surveys), reviews and meta-analyses, modelling studies without experimental data

\section{Study validity assessment}

Studies will be critically appraised according to the criteria described in Table 2. These criteria were established on the basis of the framework proposed by Vandenberg et al. [37] and the knowledge of the experts in the review team (experts in ecotoxicology, coral ecotoxicology, coral biology and ecology, and risk assessment of chemicals). The overall risk of bias for a study will be low if all criteria leading to a low risk of bias are met; medium if at least one criterion leads to a medium risk of bias, with all others leading to a low risk of bias; and high if at least one criterion leads to a high risk of bias (Table 2). During narrative synthesis, the results of studies with a low overall risk of bias will be first synthesised, and then the consistency with the results of studies with a medium and high risk of bias will be assessed. The quantitative synthesis will consist in determining toxicity thresholds (TTs): for each chemical, outcome and species, the highest concentration-longest duration tested at which no statistically significant adverse effect is observed will be determined (see Sect. "Data synthesis and presentation"). Toxicity thresholds will be determined first considering studies with low overall risk of bias, and then also considering studies with a medium and high risk of bias.

Critical appraisal will be shared between two reviewers who will independently assess a sample of studies (1\%) and discuss any disagreements before the actual critical appraisal to ensure consistency. Additionally, all doubtful cases will be identified during the assessment and double-checked by experts from the review team, and a minimum of $10 \%$ of studies will be double-checked by another reviewer. We will ensure that reviewers never have to critically appraise their own articles. The results of critical appraisal will be included as an appendix to the systematic review publication.

\section{Data coding and extraction strategy}

The variables presented in Table 3 will be extracted from studies. These meta-data will be added to those already extracted for the systematic map (i.e., type of study, ISO 
Table 2 Critical appraisal criteria established on the basis of the framework proposed by Vandenberg et al. [37] and the knowledge of the experts in the review team (C stands for Control, E for Exposed, B for Before, A for After, and N/A for non-applicable)

\begin{tabular}{|c|c|c|c|c|}
\hline Source of bias & Criteria & Low risk of bias & Medium risk of bias & High risk of bias \\
\hline \multirow[t]{2}{*}{ Experimental design } & What is the experimental design? & $\begin{array}{l}\text { CE } \\
\text { BA } \\
\text { BACE }\end{array}$ & & Unknown \\
\hline & $\begin{array}{l}\text { Is the experiment replicated (at } \\
\text { least one replicate; a replicate is not } \\
\text { exposed to water in contact with } \\
\text { the other replicates) }\end{array}$ & Yes & $\begin{array}{l}\text { No } \\
\text { Unknown (assumed to be No) }\end{array}$ & \\
\hline \multirow[t]{2}{*}{ Exposure } & $\begin{array}{l}\text { If a solvent is used, is a solvent } \\
\text { control present? }\end{array}$ & $\begin{array}{l}\text { Yes } \\
\text { N/A }\end{array}$ & $\begin{array}{l}\text { No } \\
\text { Unknown (assumed to be No) }\end{array}$ & \\
\hline & $\begin{array}{l}\text { Have effective exposure concentra- } \\
\text { tions been measured? }\end{array}$ & Yes & $\begin{array}{l}\text { No } \\
\text { Unknown (assumed to be No) }\end{array}$ & \\
\hline Selection & $\begin{array}{l}\text { Are there differences at baseline } \\
\text { between groups } C \text { and } \mathrm{E} \text { ? (including } \\
\text { difference in exposure environment, } \\
\text { difference in biological model, } \\
\text { difference in the set of individuals } \\
\text { allocated to each group) }\end{array}$ & $\begin{array}{l}\text { No } \\
\text { N/A (for BA design) }\end{array}$ & $\begin{array}{l}\text { Yes but the effect is controlled and null } \\
\text { For in situ studies: yes but an } \\
\text { attempt to minimize differences is } \\
\text { made }\end{array}$ & $\begin{array}{l}\text { Yes (detail) } \\
\text { Unknown (assumed to be Yes) }\end{array}$ \\
\hline Performance & $\begin{array}{l}\text { Are there differences in the way } \\
\text { groups } C \text { and } E \text { (or B and A) are } \\
\text { treated throughout the experiment? }\end{array}$ & No & & $\begin{array}{l}\text { Yes (detail) } \\
\text { Unknown (assumed to be Yes) }\end{array}$ \\
\hline Detection & $\begin{array}{l}\text { Are there differences in the way the } \\
\text { outcomes of groups } C \text { and } E \text { (or B } \\
\text { and A) are assessed? }\end{array}$ & No & & $\begin{array}{l}\text { Yes (detail) } \\
\text { Unknown (assumed to be Yes) }\end{array}$ \\
\hline Exclusion & $\begin{array}{l}\text { Are there differences in the way } \\
\text { groups } C \text { and } E \text { (or } B \text { and } A \text { ) are } \\
\text { removed from the study? }\end{array}$ & No & & $\begin{array}{l}\text { Yes (detail) } \\
\text { Unknown (assumed to be Yes) }\end{array}$ \\
\hline Other & $\begin{array}{l}\text { Is there another source of bias? (e.g., } \\
\text { reporting bias, insufficient descrip- } \\
\text { tion of the methods, an unforeseen } \\
\text { event that occurred during the } \\
\text { experiment) }\end{array}$ & No & Yes minor (detail) & Yes major (detail) \\
\hline
\end{tabular}

3166 country or territory name, and geographical coordinates or location). At this step, studies will be split into cases, corresponding to an individual concentrationduration tested in an experiment, unless there are no results to extract. Only studies performed in standard abiotic conditions will be extracted, except studies testing effects of elevated temperature and low $\mathrm{pH}$ (see Sect. "Potential effect modifiers/reasons for heterogeneity").

The data extraction strategy will depend on the outcome and exposure categories considered (Table 4). First, for all exposure categories and for outcomes related to coral mortality, growth, settlement, fertilisation, symbiont density (bleaching) and photosynthesis performance, quantitative data will be extracted from text, tables and figures. The package metaDigitise [38] in the R environment [39] will be used to extract data from figures. For each case, sample size, mean and a measure of variation of the mean (e.g., standard deviation) will be extracted for both the control and the exposed group.

Second, narrative results will be extracted for the exposure categories Detergent, Dispersant,
Microplastic, Nanoparticle, Pharmaceutical, UV filter, and Other, as they have a relatively smaller total number of studies $(<200)$ than the Hydrocarbon (401), Metal (497), and Pesticide (396) categories [33], and therefore we expect relatively few quantitative results to be available for them. Narrative results will be extracted only for outcomes that will not undergo extraction of quantitative results (Table 4).

During data extraction, the missing or unclear information will be coded as such. Data extraction will be performed by two reviewers in a sequential process by exposure category. Data from one category will be extracted by one or both reviewers, and then $10 \%$ of the cases extracted by one reviewer will be doublechecked by the other reviewer to check for consistency. Any disagreements will be discussed and solved and the review team will give expert advices. This will enable consistency to be checked throughout the extraction process. The two reviewers will also discuss together any difficult cases during the extraction with the possibility of involving experts from the review team if 
Table 3 Variables that will be extracted

\begin{tabular}{|c|c|}
\hline Variable & Description \\
\hline Taxon & Name of the taxon (coded from the systematic map) \\
\hline Population exposed & $\begin{array}{l}\text { Description of the population exposed (e.g., coral nubbin with length, } \\
\text { larvae with age, egg-sperm bundle) }\end{array}$ \\
\hline Life stage & $\begin{array}{l}\text { Developmental stage of the population exposed (adult, juvenile, larval, } \\
\text { gamete) }\end{array}$ \\
\hline Control & Description of the control \\
\hline Solvent & Description of the solvent and concentration used if any \\
\hline Exposure & $\begin{array}{l}\text { Exposure coded from the systematic map with more complete description } \\
\text { if necessary }\end{array}$ \\
\hline Nominal concentration & Nominal concentration with unit \\
\hline Effective concentration & $\begin{array}{l}\text { Concentration(s) actually measured with unit and time measured (e.g., at } \\
\text { the beginning and/or the end of the experiment) }\end{array}$ \\
\hline Duration & $\begin{array}{l}\text { Duration of exposure with unit. If several durations are available for one } \\
\text { exposure concentration in a test, the longest duration will be extracted }\end{array}$ \\
\hline Type of system & $\begin{array}{l}\text { The type of experimental system (e.g., petri dish, beaker, tank, microcosm, } \\
\text { mesocosm, in situ) }\end{array}$ \\
\hline Temperature & Mean seawater temperature during exposure in ${ }^{\circ} \mathrm{C}$ \\
\hline $\mathrm{pH}$ & Mean seawater pH during exposure \\
\hline Measured outcome & $\begin{array}{l}\text { Outcome coded from the systematic map with more complete description } \\
\text { if necessary. Detail will be provided here in case the outcome was meas- } \\
\text { ured on a different developmental stage than the one exposed }\end{array}$ \\
\hline Time after exposure & Time when the outcome was measured after exposure ceased \\
\hline $\begin{array}{l}\text { Quantitative result* } \\
\text { *Extraction only for outcomes related to coral mortality, growth, settle- } \\
\text { ment, symbiont density and photosynthesis }\end{array}$ & $\begin{array}{l}\text { Sample size, mean, type and measure of variation of the mean (e.g., stand- } \\
\text { ard deviation) for the control and the exposed group }\end{array}$ \\
\hline $\begin{array}{l}\text { Narrative result* } \\
\text { *Extraction only for the exposure categories Detergent, Dispersant, Micro- } \\
\text { plastic, Nanoparticle, Pharmaceutical, UV filter, and Other, and only for } \\
\text { outcomes that will not undergo extraction of quantitative results }\end{array}$ & Description of a statistically tested result \\
\hline
\end{tabular}

Table 4 Summary of the data extraction and synthesis strategy

\begin{tabular}{lll}
\hline & Hydrocarbon, metal, pesticide & $\begin{array}{l}\text { Detergent, dispersant, microplastic, nanoparticle, } \\
\text { pharmaceutical, UV filter, and other }\end{array}$ \\
\hline $\begin{array}{l}\text { Growth, fertilisation, mortality, settle- } \\
\text { ment, symbiont density, photosyn- } \\
\text { thesis }\end{array}$ & $\begin{array}{l}\text { Quantitative synthesis: extraction of quantitative } \\
\text { results }\end{array}$ & Quantitative synthesis: extraction of quantitative results \\
$\begin{array}{l}\text { All other outcome categories } \\
\text { Not included in synthesis: no data extracted }\end{array}$ & $\begin{array}{l}\text { Narrative synthesis of the findings: extraction of narra- } \\
\text { tive results }\end{array}$ \\
\hline
\end{tabular}

deemed relevant. All data extracted will be open access and included as an appendix to the systematic review publication.

\section{Potential effect modifiers/reasons for heterogeneity} Based on the expertise of experts from the review team, the following potential effect modifiers will be considered:

- Chemical concentration and duration of exposure;
- Taxon exposed;

- Developmental stage exposed;

- Seawater temperature during exposure;

- Seawater pH during exposure.

Indeed, taxonomic group and life stage are the main biotic factors influencing sensitivity to chemical exposure [40], while temperature and $\mathrm{pH}$ are among the main abiotic factors modifying the toxicity of chemicals [40]. The 
latter were particularly selected given the current warming and acidification of the oceans [9].

\section{Data synthesis and presentation}

First, the studies included in the systematic review will be described in a narrative synthesis of the characteristics of individual primary studies (e.g., population, exposure and outcomes studied) with descriptive statistics, tables and figures. The studies informing the quantitative synthesis will also be described separately.

Then, the findings will be synthesised according to a strategy depending on the type of exposure and outcome (Table 4). The main focus of the review will be the quantitative synthesis conducted for the outcomes related to coral mortality, growth, settlement, fertilisation, symbiont density (bleaching) and photosynthesis performance. However, according to the systematic map [33], the number of studies that will support the quantitative synthesis will be relatively smaller $(<200)$ for the exposure catego- quantitative data. In addition, they have lethal and sublethal toxicity endpoints over the entire coral life cycle and concern both the coral animal and its symbionts. Sample size, mean, and variation of the mean (standard deviation, standard error or confidence intervals) for the control and the exposed group will have to be reported in order to be included in the quantitative synthesis. An estimate of the effect size will be computed for each case using the standardised mean difference (Hedges' d, [41]):

$$
d_{i}=\left(\left(\bar{X}_{\text {treatment }_{i}}-\bar{X}_{\text {control }_{i}}\right) / S_{\text {pooled }_{i}}\right) \times J_{i}
$$

where $\bar{X}_{\text {treatment }_{i}}$ is the mean for the exposed group, $\bar{X}_{\text {control }_{i}}$ is the mean for the control group, $S_{\text {pooled }_{i}}$ is the pooled standard deviation for the two groups and $J_{i}$ is a correction term for small sample size. A positive (or negative) $d_{i}$ means that the outcome measured is higher (or lower) in the exposed group than in the control group, and a null $d_{i}$ means that there is no difference between the exposed and the control groups. The pooled standard deviation is calculated as:

$$
S_{\text {pooled }_{i}}=\sqrt{\frac{\left(n_{\text {treatment }_{i}}-1\right) \times S D_{\text {treatment }_{i}}^{2}+\left(n_{\text {control }_{i}}-1\right) \times S D_{\text {control }_{i}}^{2}}{n_{\text {treatment }_{i}}+n_{\text {control }_{i}}-2}}
$$

ries Detergent, Dispersant, Microplastic, Nanoparticle, Pharmaceutical, UV filter, and Other, than for the Hydrocarbon (401), Metal (497), and Pesticide (396) categories. Because relatively few quantitative results are expected to be available for these categories, a narrative synthesis of the findings of individual primary studies will be produced to provide additional information for these exposure categories. This narrative synthesis will be conducted for the outcome categories that will not undergo extraction of quantitative results, and will not concern the categories Hydrocarbon, Metal, and Pesticide, due to limited resources and time (Table 4).

\section{Quantitative synthesis}

A quantitative synthesis will be conducted for the outcomes related to coral mortality, growth, settlement, fertilisation, symbiont density (bleaching) and photosynthesis performance (Table 4). These outcomes were chosen because they are expected to have the most and the correction term $J_{i}$ as:

$$
J_{i}=1-\frac{3}{4 \times\left(n_{\text {treatment }_{i}}+n_{\text {control }_{i}}-2\right)-1}
$$

where $n_{\text {treatment }}, n_{\text {control }}, S D_{\text {treatment }}$, and $S D_{\text {control }_{i}}$ are the sample size and the standard deviation for the exposed and the control group, respectively. The variance of $d_{i}$ will be calculated as [42]:

$$
\operatorname{var}\left(d_{i}\right)=\frac{n_{\text {treatment }}+n_{\text {control }_{i}}}{n_{\text {treatment }_{i}} \times n_{\text {control }_{i}}}+\frac{d_{i}^{2}}{2\left(n_{\text {treatment }_{i}}+n_{\text {control } \left._{i}\right)}\right)}
$$

To determine the ecotoxicological effects of chemicals on corals, 95\% confidence intervals will be computed for each effect size estimate $d_{i}$ as $d_{i} \pm 1.96 * \sqrt{v a r_{i}}$, to identify whether each $d_{i}$ is statistically significantly different from zero. All concentrations and durations of exposure will be standardised and the data will be 
synthesised, if possible, through the determination of a toxicity threshold (TT) corresponding to the highest concentration-longest duration tested at which no statistically significant adverse effect is observed, compared to the control. The TT will be determined by outcome, chemical and species under standard temperature and $\mathrm{pH}$ conditions, first considering studies with low overall risk of bias, and then also considering studies with a medium and high risk of bias. The impact of increasing temperature and acidification on TTs will be assessed by determining TTs under conditions of high temperature $\left(\geq 30{ }^{\circ} \mathrm{C}\right)$ and low $\mathrm{pH}(<8, \mathrm{ca}$. the ocean global average $\mathrm{pH}$ value [43]) and comparing them to those determined under standard conditions.

Because our synthesis approach will be the definition of thresholds and not the classical computation of a mean effect size, publication bias analysis and sensitivity analysis will not be classically performed (i.e., with funnel plot, Egger's regression test, or plot of influence diagnostics). The risk that TTs are biased because unpublished studies with statistically non-significant results are not included in synthesis (publication bias) is inherently limited. Indeed, if these putative nonincluded studies tested exposure concentrations-durations lower than the TT, there is no consequence, as the TT is the highest concentration-longest duration tested at which no statistically significant adverse effect is observed. However, if these putative non-included studies tested exposure concentrations-durations higher than the TT, this means that the TT could be underestimated, which has limited consequences from an environmental perspective (i.e., the TT is overly conservative). The risk of publication bias, as well as the influence of individual studies on each toxicity threshold (sensitivity analysis), will therefore be shown graphically, by plotting the effect size estimates $d_{i}$ as a function of increasing exposure concentrations-durations.

\section{Narrative synthesis}

A narrative synthesis of the findings of individual primary studies will be produced for the exposure categories Detergent, Dispersant, Microplastic, Nanoparticle, Pharmaceutical, UV filter, and Other, and for the outcome categories that will not undergo extraction of quantitative results (Table 4). Statistically significant results will be summarized in narrative tables and a narrative synthesis will be written, distinguishing results from studies with low, medium and high risk of bias. Results reported but not statistically tested will not be included in the narrative synthesis of the findings. The list of all studies not included in the quantitative or the narrative synthesis of the findings will be provided with reason of why they could not be included.

\section{Supplementary Information}

The online version contains supplementary material available at https://doi. org/10.1186/s13750-021-00250-y.

Additional file 1. ROSES systematic review protocols checklist. ROSES form for systematic review protocols version 1.0.

Additional file 2. Description of the search strategy. Details of the search strategy used for the systematic map and the search update planned for the systematic review.

\section{Acknowledgements}

Not applicable.

\section{Authors' contributions}

DYO and OP defined the first set of critical appraisal criteria that was revised by CFP, IDC, LH, and RS, and further reviewed by CC, KB, and MG. All authors defined the set of variables to extract based on a draft proposed by DYO. This paper is based on a draft written by DYO. All authors read, commented and approved the final manuscript.

\section{Funding}

This work was funded by the French Office for Biodiversity (OFB) and the French National Museum of Natural History (MNHN).

Availability of data and materials

All data generated or analysed during this study are included in this published article and its additional information files.

\section{Declarations}

Ethics approval and consent to participate

Not applicable.

Consent for publication

Not applicable.

\section{Competing interests}

In 2018, CFP collaborated with the private company "L'Oréal" for a research work on the impact of sunscreen ingredients on a coral species. $\mathrm{LH}$ is currently conducting research on the effects of cosmetic ingredients on young stages of corals of French Polynesia for the private company "Comptoir du Monoi".

\section{Author details}

${ }^{1}$ Direction de l'Expertise, Muséum National d'Histoire Naturelle (MNHN), 75005 Paris, France. ${ }^{2}$ Office Français de la Biodiversité (OFB), 94300 Vincennes, France. ${ }^{3}$ Equipe Ecophysiologie Corallienne, Centre Scientifique de Monaco, MC-98000 Monaco, Monaco. ${ }^{4}$ Laboratoire Molécules de Communication et Adaptation des Microorganismes (MCAM), UMR 7245, CNRS, Muséum National d'Histoire Naturelle (MNHN), 75005 Paris, France. ${ }^{5}$ Laboratoire d'Excellence CORAIL, 66860 Perpignan, France. ${ }^{6}$ USR 3278 CRIOBE, PSL Université Paris: EPHE, UPVD, CNRS, 98729 Papetoai, Mo'orea, French Polynesia. ${ }^{7}$ French Agency for Food, Environmental and Occupational Health and Safety (ANSES), 94701 Maisons-Alfort Cedex, France. ${ }^{8}$ Laboratoire de Biologie des Organismes et Ecosystèmes Aquatiques (BOrEA), Muséum National d'Histoire Naturelle, CNRS, SU, IRD, UCN, UA EcoFunc, Aviv, 75005 Paris, France. ${ }^{9}$ Biocapteurs Analyses Environnement, University of Perpignan via Domitia, 66000 Perpignan, France. ${ }^{10}$ Laboratoire de Biodiversité et Biotechnologies Microbiennes (LBBM), Sorbonne Universités, CNRS, 66650 Banyuls sur Mer, France. ${ }^{11}$ Institut de Systématique, Evolution, Biodiversité (ISYEB), Muséum National d'Histoire Naturelle, CNRS, Sorbonne Université, EPHE, Université Des Antilles, 75005 Paris, France.

12 UMS Patrimoine Naturel (PatriNat), OFB, MNHN, CNRS, 75005 Paris, France.

Received: 10 August 2021 Accepted: 27 November 2021

Published online: 11 December 2021 


\section{References}

1. Hoeksema BW. The hidden biodiversity of tropical coral reefs. Biodiversity. 2017:18:8-12.

2. Fisher R, O'Leary RA, Low-Choy S, Mengersen K, Knowlton N, Brainard RE, et al. Species richness on coral reefs and the pursuit of convergent global estimates. Curr Biol. 2015;25:500-5.

3. Burke L, Reytar K, Spalding M, Perry A. Reefs at risk revisited. Washington: World Resources Institute; 2011.

4. Ferrario F, Beck MW, Storlazzi CD, Micheli F, Shepard CC, Airoldi L. The effectiveness of coral reefs for coastal hazard risk reduction and adaptation. Nat Commun. 2014:5:1-9.

5. Cesar H, Burke L, Pet-Soede L. The economics of worldwide coral reef degradation [Internet]. International Coral Reef Action Network; 2003. http://www. icran.org/pdf/cesardegradationreport.pdf.

6. Barlow J, França F, Gardner TA, Hicks CC, Lennox GD, Berenguer E, et al. The future of hyperdiverse tropical ecosystems. Nature. 2018:559:517-26.

7. Ellis JI, Jamil T, Anlauf H, Coker DJ, Curdia J, Hewitt J, et al. Multiple stressor effects on coral reef ecosystems. Glob Change Biol. 2019;25:4131-46.

8. Souter D, Planes S, Wicquart, Jérémy, Logan, Murray, Obura, David, Staub, Francis. Status of Coral reefs of the World: 2020 [Internet]. 2021. https://gcrmn. net/2020-report/.

9. Hoegh-Guldberg O, Poloczanska ES, Skirving W, Dove S. Coral reef ecosystems under climate change and ocean acidification. Front Mar Sci. 2017;4.

10. Hoegh-Guldberg O, Pendleton L, Kaup A. People and the changing nature of coral reefs. Reg Stud Mar Sci. 2019;30:100699.

11. Wilkinson C. Status of coral reefs of the world: 2008 . Global coral reef monitoring network and reef and rainforest research centre. Townsville; 2008.

12. Cunning R, Silverstein RN, Barnes BB, Baker AC. Extensive coral mortality and critical habitat loss following dredging and their association with remotelysensed sediment plumes. Mar Pollut Bull. 2019;145:185-99.

13. Schuhmacher H, Zibrowius H. What is hermatypic? Coral Reefs. 1985:4:1-9.

14. LaJeunesse TC, Parkinson JE, Gabrielson PW, Jeong HJ, Reimer JD, Voolstra $\mathrm{CR}$, et al. Systematic revision of symbiodiniaceae highlights the antiquity and diversity of coral endosymbionts. Curr Biol. 2018;28:2570-2580.e6.

15. Brown BE. Coral bleaching: causes and consequences. Coral Reefs 1997:16:5129-38.

16. Duprey NN, Yasuhara M, Baker DM. Reefs of tomorrow: eutrophication reduces coral biodiversity in an urbanized seascape. Glob Change Biol. 2016;22:3550-65.

17. De Barros Marangoni LF, Marques JA, Duarte GAS, Pereira CM, Calderon EN, Castro CB, et al. Copper effects on biomarkers associated with photosynthesis, oxidative status and calcification in the Brazilian coral Mussismilia harttii (Scleractinia, Mussidae). Mar Environ Res. 2017;130:248-57.

18. Prouty NG, Cohen A, Yates KK, Storlazzi CD, Swarzenski PW, White D. Vulnerability of coral reefs to bioerosion from land-based sources of pollution. J Geophys Res Oceans. 2017;122:9319-31.

19. Richmond RH, Tisthammer KH, Spies NP. The effects of anthropogenic stressors on reproduction and recruitment of corals and reef organisms. Front Mar Sci. 2018:5.

20. DeCarlo TM, Cohen AL, Barkley HC, Cobban Q, Young C, Shamberger KE, et al. Coral macrobioerosion is accelerated by ocean acidification and nutrients. Geol GeoScienceWorld. 2015;43:7-10.

21. Wooldridge SA. Water quality and coral bleaching thresholds: formalising the linkage for the inshore reefs of the Great Barrier Reef, Australia. Mar Pollut Bull. 2009:58:745-51.

22. Donovan MK, Adam TC, Shantz AA, Speare KE, Munsterman KS, Rice MM, et al. Nitrogen pollution interacts with heat stress to increase coral bleaching across the seascape. Proc Natl Acad Sci. 2020;117:5351-7.

23. Zaneveld JR, Burkepile DE, Shantz AA, Pritchard CE, McMinds R, Payet JP, et al. Overfishing and nutrient pollution interact with temperature to disrupt coral reefs down to microbial scales. Nat Commun. 2016;7:1-12.

24. MacNeil MA, Mellin C, Matthews S, Wolff NH, McClanahan TR, Devlin M, et al. Water quality mediates resilience on the Great Barrier Reef. Nat Ecol Evol. 2019:3:620-7.

25. European Commission. Technical Guidance Document on Risk Assessment in support of Commission Directive 93/67/EEC 368 on risk assessment for new notified substances and Commission Regulation (EC) No 1488/94 on risk assessment 369 for existing substances and Commission Directive (EC) 98/8 on biocides. 2nd Edition. [Internet]. 2003. https://echa.europa.eu/documents/ 10162/16960216/tgdpart2_2ed_en.pdf.
26. van Dam JW, Negri AP, Uthicke S, Mueller JF. Chapter 9: chemical pollution on coral reefs: exposure and ecological effects. Ecol Impacts Toxic Chem. 2011; 187-211.

27. Jones R. The ecotoxicological effects of Photosystem II herbicides on corals. Mar Pollut Bull. 2005:51:495-506.

28. Turner NR, Renegar DA. Petroleum hydrocarbon toxicity to corals A review. Mar Pollut Bull. 2017:119.

29. Mitchelmore CL, Burns EE, Conway A, Heyes A, Davies IA. A critical review of organic ultraviolet filter exposure, hazard, and risk to corals. Environ Toxicol Chem. 2021;40:967-88

30. Joannot P. Les récifs coralliens, un écosystème à protéger. Sci Au Présent 2010. Encyclopedia Universalis; 2010. p. 204-14.

31. Sheppard C, Davy S, Pilling G, Graham N. Coral reefs: biodiverse and productive tropical ecosystems. Biol Coral Reefs Second Ed. Oxford University Press. Oxford: Oxford University Press; 2018.

32. Ifrecor. Etat de santé des récifs coralliens, herbiers marins et mangroves des outre-mer français. Bilan 2020. 2020 p. 335

33. Ouédraogo D-Y, Delaunay M, Sordello R, Hédouin L, Castelin M, Perceval O, et al. Evidence on the impacts of chemicals arising from human activity on tropical reef-building corals; a systematic map. Environ Evid. 2021;10.

34. Collaboration for Environmental Evidence. Guidelines and Standards for Evidence synthesis in Environmental Management. Version 5.0 (AS Pullin, GK Frampton, B Livoreil \& G Petrokofsky, Eds) www.environmentalevidence.org/ information-for-authors. [Accessed 12 Nov 2019] [Internet]. Pullin A, Frampton G, Livoreil B, Petrokofsky G, editors. 2018 [cited 2019 Nov 12]. www.envir onmentalevidence.org/information-for-authors.

35. Haddaway N, Macura B, Whaley P, Pullin A. ROSES for systematic review protocols. Version 1.0. 2017.

36. Ouédraogo D-Y, Sordello R, Brugneaux S, Burga K, Calvayrac C, Castelin M, et al. What evidence exists on the impacts of chemicals arising from human activity on tropical reef-building corals? A systematic map protocol. Environ Evid. 2020;9:18.

37. Vandenberg LN, Ågerstrand M, Beronius A, Beausoleil C, Bergman Å, Bero LA, et al. A proposed framework for the systematic review and integrated assessment (SYRINA) of endocrine disrupting chemicals. Environ Health. 2016:15:74.

38. Pick JL, Nakagawa S, Noble DWA. Reproducible, flexible and high-throughput data extraction from primary literature: the metaDigitise r package. Methods Ecol Evol. 2019;10:426-31.

39. R Core Team. R: A Language and Environment for Statistical Computing [Internet]. Vienna, Austria: R Foundation for Statistical Computing; 2021. https:// www.R-project.org/.

40. Wright DA, Welbourn P. Factors affecting toxicity. Environ Toxicol. Cambridge: Cambridge University Press; 2002. p. 218-48.

41. Hedges LV, Olkin I. Statistical methods for meta-analysis. Orlando: Academic Press; 1985.

42. Hedges LV. Estimation of effect size from a series of independent experiments. Psychol Bull. 1982;92:490-9.

43. Jiang L-Q, Carter BR, Feely RA, Lauvset SK, Olsen A. Surface ocean pH and buffer capacity: past, present and future. Sci Rep. 2019:9:18624.

\section{Publisher's Note}

Springer Nature remains neutral with regard to jurisdictional claims in published maps and institutional affiliations.

Ready to submit your research? Choose BMC and benefit from

- fast, convenient online submission

- thorough peer review by experienced researchers in your field

- rapid publication on acceptance

- support for research data, including large and complex data types

- gold Open Access which fosters wider collaboration and increased citations

- maximum visibility for your research: over 100M website views per year

At BMC, research is always in progress.

Learn more biomedcentral.com/submissions 